\title{
Anterior glenoid kenarın rekonstrüksiyon teknikleri ve klinik sonuçları
}

\author{
Anterior glenoid rim reconstruction techniques and clinical outcomes
}

\author{
Kerem Bilsel, Hakan Batuhan Kaya, Mehmet Kapıcıoğlu
}

Bezmialem Vakıf Üniversitesi, Ortopedi ve Travmatoloji Ana Bilim Dalı, İstanbul

\begin{abstract}
Tekrarlayan omuz çıkığı olgularında, özellikle glenoid anterior kenarda kemik defekti varsa yumuşak doku prosedürleri tedavide yetersiz kalabilir. Omuz instabilitesindeki yeni konseptler ve defekt ölçüm yöntemleri tedaviyi yönlendirmede biz ortopedik omuz cerrahlarına kılavuzluk etmektedir. Kemik defektlerinin tedavisinde kemik blok yöntemleri öne çıkmaktadır. Glenoid anterior kenar rekonstrüksiyonunda kullanılacak blok seçenekleri otogreft ya da allogreft şeklinde olabilir. Cerrahi tedavi tarihi Latarjet prosedüründen doğal glenoid ile anatomik olarak daha iyi uyum sağlayabilecek yeni teknikler ve greft seçeneklerine doğru evrilmiştir. Bu işlemler gelişen ileri teknolojik aletler ve tespit materyalleriyle tam artroskopik olarak da yapılabilmektedir.
\end{abstract}

Anahtar sözcükler: glenoid kemik kaybı; kemik blok; Latarjet

\begin{abstract}
Soft tissue procedures may be insufficient in the treatment of recurrent shoulder dislocations, especially if there is a bone defect at the anterior glenoid border. New concepts and defect measurement methods in shoulder instability guide shoulder surgeons in the treatment modalities. Bone block methods come to the fore in the treatment of bone defects. The block options to be used in glenoid anterior margin reconstruction can be autograft or allograft. The history of surgical treatment has evolved from the Latarjet procedure to new techniques and graft options that can better fit the native glenoid anatomically. These procedures can also be performed fully arthroscopically, with advanced technological tools and fixation materials.

Key words: glenoid bone loss; bone block; Latarjet
\end{abstract}

Kemik blok ameliyatları; anterior labroligamentöz yapıları içeren ciddi yumuşak doku yaralanması ile glenoid kemik kaybı olan veya yumuşak doku prosedürleri sonrası gelişen nüks vakalarında da iyi bir seçenektir. ${ }^{[6]}$ Inferior glenohumeral ligamanın avülsiyonu (Humeral Avulsion of Inferior Glenohumeral Ligament, HAGL) lezyonu sonrası gelişen instabilite ve rotator manşet yırtıkları varlığında gelişen instabilitede kemik blok ameliyatları tercih edilebilir. ${ }^{[7]}$ Yüksek riskli kontakt spor yapanlarda da özellikle güvenli bir seçenek olarak öne çıkmaktadır. ${ }^{[3]}$

Greft pozisyonun; glenoid kenarına anatomik (flush) veya $5 \mathrm{~mm}$ 'den daha az medialinde olması, glenoid ekvatorunun inferiorunda olması, dekortikasyonun tam olması, tespit vidasının posterior korteksi tutması ve vidanın eklem içi penetrasyonunun olmaması bu cerrahinin başarısı için olmazsa olmaz aşamalardır. ${ }^{[8,9]}$

İletişim / Contact: Dr. Kerem Bilsel •E-posta / E-mail: kbilsel@gmail.com

ORCID iD: Kerem Bilsel, 0000-0002-7402-756X • Hakan Batuhan Kaya, 0000-0002-9788-6578 • Mehmet Kapıcıoğlu, 0000-0002-6987-4270

Geliş / Received: 24 Aralık 2021 • Kabul / Accepted: 1 Şubat 2022 
Artroskopik cerrahinin yaygınlaşmasıyla gelişen cerrahi beceri ve teknolojik aletlerin kullanımıyla kemik blok işlemleri tamamen artroskopik yapılabilir hâle gelmiştir. Artroskopik cerrahinin avantajları arasında; daha az cerrahi skar, düşük enfeksiyon oranı, daha az doku hasarı, hızlı rehabilitasyon görülmektedir. Artroskopik cerrahi ile eklem içi daha iyi değerlendirilebilir, biseps patolojileri ve SLAP (Superior Labrum Anterior Posterior) lezyon değerlendirmesi yapılabilir. Cerrahi başarıyı en fazla etkileyen greft pozisyonlamasının artroskopik olarak daha iyi değerlendirilebileceğini belirten Lafosse, artroskopik kemik blok tekniğini (artro-Latarjet) tanımlamış ve özgün cerrahi aletler ve kılavuzlar geliştirmiştir. ${ }^{[10]}$

\section{ANTERIOR GLENOID KEMIK KAYBININ DEĞERLENDIRILMESI VE ÖLÇÜLMESi}

Radyografi kemik kaybını değerlendirmede hâlâ hızlı ve ucuz bir yöntemdir ve ilk basamak olarak kullanılmaktadır. Standart omuz ön-arka radyografilerde glenoid önünde sklerotik hattın görülmesi kemik kaybı için değerlidir. ${ }^{[11]}$ Bazı spesifik radyografi (West Point ve Garth grafileri) görüntüleri olsa da elde edilmeleri zordur ve kemik kaybının güvenilir biçimde ölçülmesine izin vermezler. ${ }^{[12]}$ Bilgisayarlı Tomografi (BT), anterior glenoid kemik kaybının değerlendirilmesinde altın standarttır. Humerus başının çıkartılmasıyla elde edilen üç boyutlu glenoid rekonstrüksiyonu kemik kaybının en doğru şekilde ölçülmesine izin verir (Şekil 1). ${ }^{[13]}$ Kemik kaybını ölçmede farklı yöntemler vardır; genişlik ölçüm teknikleri (Griffith index), daire yüzey alanı ölçüm teknikleri (Pico yöntemi) veya bunların varyasyonları sayılabilir (Şekil 2). ${ }^{[14,15]}$ Bilgisayarlı tomografi tetkiki hâlâ radyasyon maruziyeti ciddi bir endişe kaynağı oluşturmaktadır. Manyetik rezonans görüntüleme (MRG, MRI) ile bu

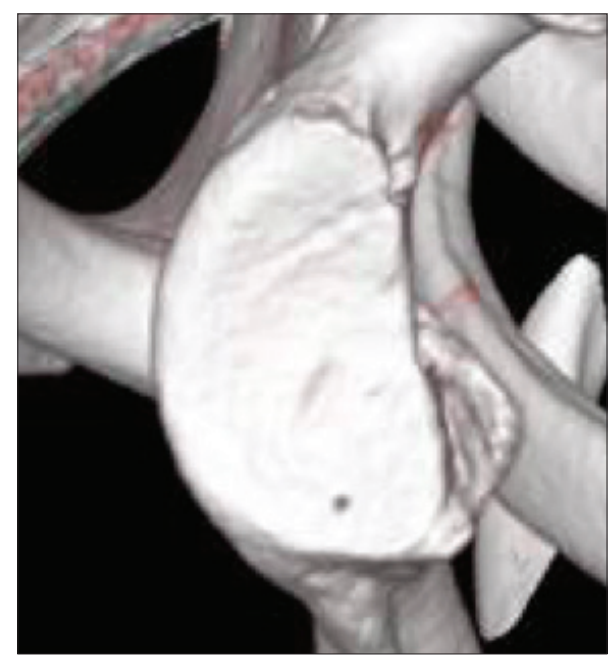

Şekil 1. Humerus çıkartılmış 3D glenoid BT'si.

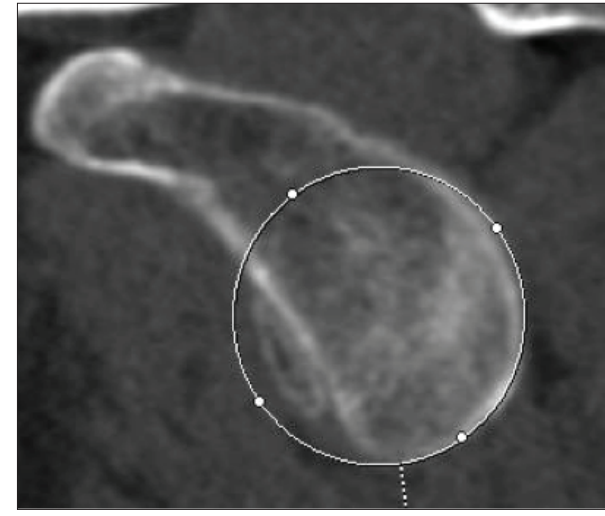

Şekil 2. Pico yöntemine göre anterior glenoid kemik kaybı ölçümü.

radyasyon maruziyetinden sakınılabilir. Manyetik rezonans görüntülemenin yaralanmayla ilişkili yumuşak doku görüntülemesi BT'ye göre çok üstün olmasına rağmen, hâlâ glenoid kemik kaybının nicel ölçülmesinde BT daha üstün görülmektedir. Yeni üç boyutlu (3D) MR teknikleri ile BT'ye eşdeğer ölçümler değerlendirilse de kullanımı yaygınlaşmamıştır. ${ }^{[16]}$

\section{ANTERIOR GLENOID KEMIK KAYBININ TEDAVISi}

Tekrarlayan anterior omuz çıkıklarının tedavisi 1980'lerde artroskopik tekniklerin gelişmesiyle beraber ilk basamak olarak artroskopik Bankart tamiri yaygınlık kazanmıştır. ${ }^{[10]}$ Burkhart'ın tekrarlayan omuz çıkıklarında ters armut şekilli (inverted pear-shaped) glenoidlerde (kemik kaybı >\%25) artroskopik Bankart tamirinin yüksek başarısızlıkla sonuçlandığı makalesi paradigma kaymasına neden olmuştur. ${ }^{[2]}$ Glenoid kemik kaybı ile Bankart tamirinin başarısızlığı arasındaki ilişki daha belirgin hâle geldikçe araştırmacılar "Ne kadar glenoid kaybı yumuşak doku prosedürleriyle tedavi edilebilir?" sorusunu sormaya başladılar. Biyomekanik modeller \%20 anterior glenoid kemik kaybı olduğunda, normal glenohumeral kemik temas basınçlarını geri getirmenin ve dislokasyonu önlemenin mümkün olmadığını doğrulamıştır. ${ }^{[17]}$ Sonralarında glenoid kemik kaybındaki değerin \%17,5; $\% 15$ ve $\% 13,5$ olmasının bile kritik olabileceğini gösteren araştırmalar yayınlanmıştır. ${ }^{[18-20]}$

Sıklıkla eşlik eden Hill-Sachs lezyonu (HSL) olan humerus başı posterior kısmının artan dış rotasyon derecelerinde angaje olması ile çıkık riskini arttırabilir (Şekil 3). Böylelikle bipolar kemik defekti olan hastalarda humerus başındaki defekti doldurmak için Remplissage işlemi gerekebilir. Remplissage prosedürü; infraspinatus tendonunu ve arka kapsülü defekt olan humerus başına doldurmak, tenodez etmek işlemidir ve artroskopik Bankart tamirine eklenir. Böylelikle HSL glenoid anterior 


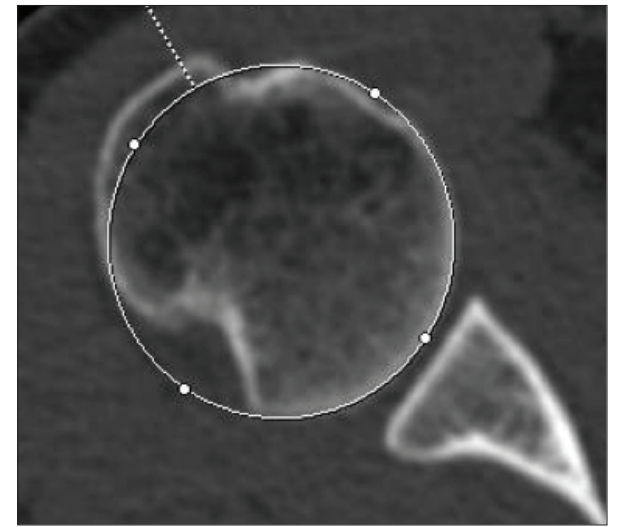

Şekil 3. Aksiyel omuz BT kesitinde Hill-Sachs lezyonu.

kemik kaybı olan kısma angaje olmaz ve çıkık önlenebilir. ${ }^{[2]}$ Remplissage prosedürünün en iyi endikasyonu glenoid yolu (track) konsepti ile anlaşılır. Glenoid track; glenoid anterior kemik kaybını da içeren glenoid genişliğinin \%83'üne eşittir. Humerus başındaki HSL glenoid yolunun (track) humerus başındaki iz düşümünün medialinde kalıyorsa buna off-track denir ve Remplissage prosedürünün Bankart tamirine eklenmesi önerilir. ${ }^{[21,22]}$

Kemik blok ameliyatları ile anteroposterior glenoid arkı uzatılır ve glenoid anterior kemik defekti rekonstrükte edilebilir. Sıklıkla eşlik eden HSL olan humerus başı posterior kısmının artan dış rotasyon derecelerinde angaje olmasını engeller ve çıkığı önler. Böylelikle bipolar kemik defekti olan hastalarda da kemik blok işlemleri iyi bir seçenektir. ${ }^{[3,10]}$

\section{ANTERIOR GLENOID KEMIK KAYBININ KEMIK BLOK ILE REKONSTRÜKSIYONDA SEÇENEKLER}

\section{A. OTOGREFT SEÇENEKLERi}

\section{Otolog iliak Kanat Kemik Blok Transferi:}

Glenoid kemik kaybının büyük olduğu vakalarda

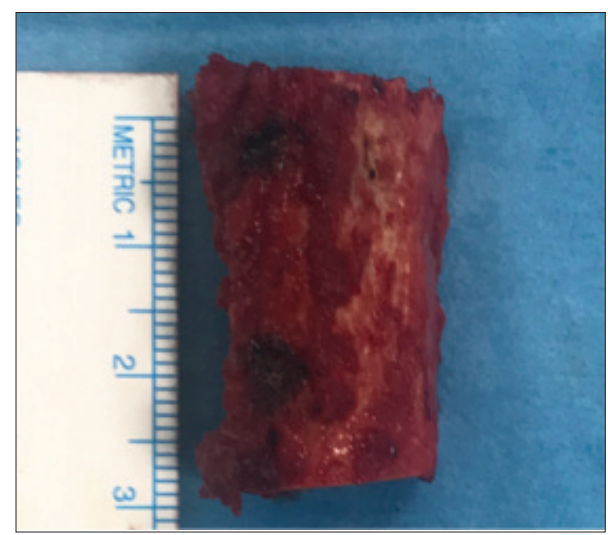

Şekil 4. Otolog iliak kanat kemik grefti.

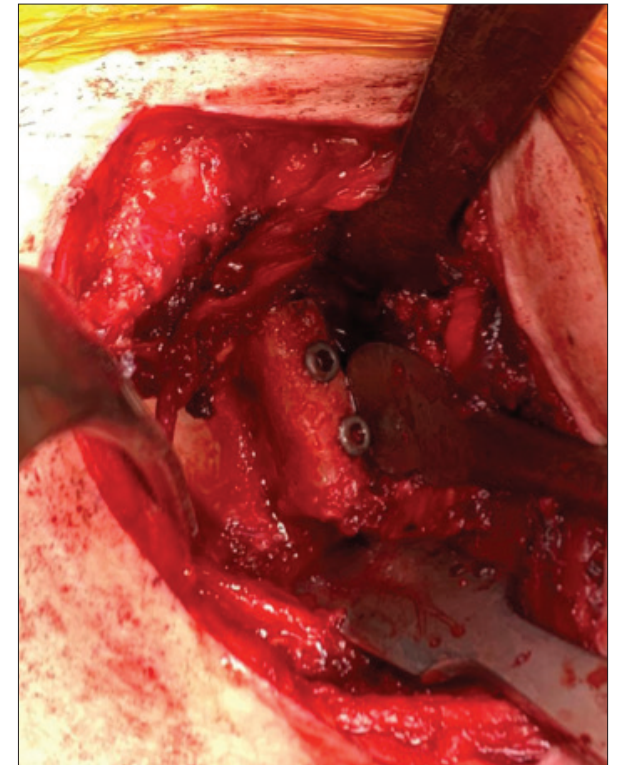

Şekil 5. Latarjet revizyonunda otolog iliak kanat kemik blok transferi.

birincil ya da başarısız korakoid transferi (Latarjet) revizyonunda tercih edilebilir (Şekil 4-5). Yüzyıllık geçmişi olan ve ilk tanımlanan tekniktir (Eden-Hybinnette tekniği). ${ }^{[23,24]}$ Orijinal teknikte greft kapsül içine tespit materyalsiz ve anatomik olmayan (non-anatomik) olarak yerleştirilmiştir. Modern tekniklerde tercih edilen eklem hattına anatomik (flush) yerleştirilmiş ve tespit materyalleri ile güçlendirilmiş tespitler tercih edilmektedir. Greft tespitinde sıklıkla vidalar tercih edilse de gelişen teknolojik aletler ve artroskopik teknikler ile kortikal düğme (cortical button) veya implantsız (implant-free) sadece dikiş materyalleri ile tespit yöntemleri de bildirilmektedir. ${ }^{[25]}$

Auffarth ve ark. otolog iliak kanat greftinin "J" şeklinde şekillendirildiği ve greftin glenoid ön kısmına önceden oluşturulmuş oluğa press-fit yerleştirildiği implantsız bir varyasyonu tanımlamışlardır. İmplant gerekmemesi, greft rezopsiyonu sonrası implant problemlerine bağlı revizyon ihtiyacının azalmasını avantaj olarak bildirmişlerdir. ${ }^{[26]}$

Artroskopik teknikler ile iliak kanat otogrefti yerleştirilebilmektedir. Greftin rotator intervalden geçirilerek yerleştirilmesiyle subskapularis miyotendinöz ünitesinin daha iyi korunması sağlanmıştır. Donor saha morbiditesi ciddi dezavantaj oluşturmakla beraber diğer kemik blok teknikleri ile benzer sonuçlar gösterilmiştir. ${ }^{[27]}$

\section{Distal Klavikula Transferi:}

Distal klavikula osteokondral otogrefti, glenoid kemik kaybına sekonder glenohumeral instabilite için yeni art- 
roskopik bir tekniktir. Teknik orijinal olarak Tokish ve ark. tarafından tarif edilmiştir ve distal 6 ila $8 \mathrm{~mm}$ klavikulanın alınması ve sütür ankorları veya kanüllü vida ile glenoide anterior rekonstrüksiyon için kullanılmasıyla gerçekleştirilir. Greft, glenoid ile uyumlu bir eklem yüzeyi sağlar, fiksasyon ve kemik birleşimi için geniş bir yüzey alanına sahiptir. Artiküler taraflı distal klavikula kemik grefti diğer seçeneklere göre kıkırdak içermesi nedeniyle daha anatomik bir seçenek gibi gözükebilir. Tokish ve ark.'nın ilk pilot çalışmasında küçük bir hasta örneği için olumlu erken sonuçlar bildirmiştir, ancak glenoid kemik kaybına bağlı tekrarlayan omuz instabilitesinin tedavisi için bu yeni tekniğin etkinliğini ve güvenliğini değerlendirmek için klinik çalışmalara ihtiyaç vardır. ${ }^{[28]}$

Greft seçeneğinin cerrahi sahaya yakınlığı ve kıkırdak içermesi avantajları olarak sayılabilirken, akromioklavikuler eklem instabilitesi ve donor saha morbiditesi dezavantaj sayılabilir.

\section{Korakoid Kemik Blok Transferi (Bristow-Latarjet Transferi):}

Glenoid anterior kenar rekonstrüksiyonunda korakoid transfer teknikleri özellikle Avrupa'da (Fransa) tercih edilen tedavi yöntemidir. Korakoid transfer yöntemleri ilk olarak 1954'te Latarjet tarafından tanımlanmıştır. 1958'de Bristow korakoid çıkıntının (prosesin) glenoid ön kısmına tespit tekniğini tanımlamıştır. 1980'de Patte, Latarjet tekniğini modifiye ederek üçlü blok 3B (bone block, belt, bumper effect) etkisini tanımlamıştır (1-Kemik blok etkisi, 2- Konjuan tendonun; abduksiyon ve dış rotasyonda anterioinferior kapsül ve inferior subskapu-

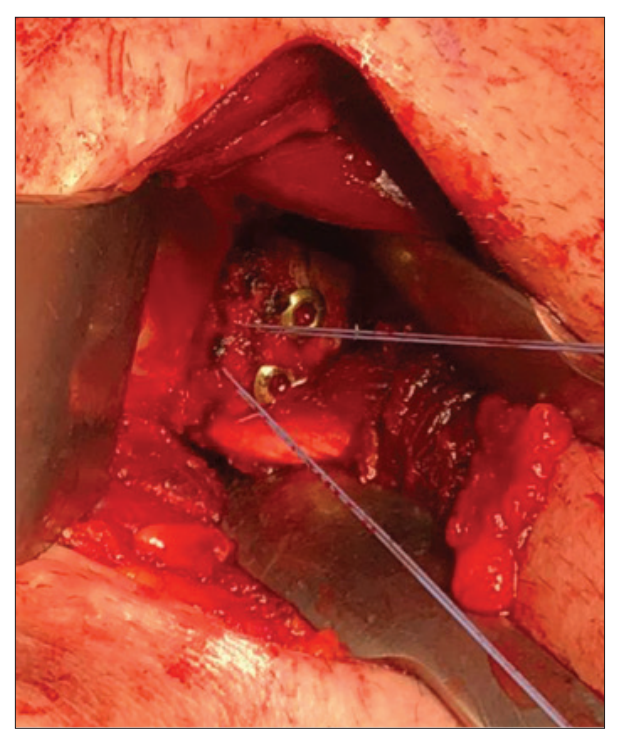

Şekil 6. Korakoid kemik blok transferi (Latarjet); ameliyat sırasındaki görüntü. laris üzerindeki askı etkisi, 3- Kapsülün korakoakromiyal ligament güdügüne dikilmesi) (Şekil 6). ${ }^{[25]}$ Cerrahi gerektiren tüm anterior glenoid defekti olan hastalara kemik blok ameliyatı uygulanabilmektedir. Hill-Sachs ve SLAP lezyonlarının, eklem içi patolojilerin Latarjet işleminin sonucunu değiştirmediğini belirten çalışmalar bulunmaktadır. ${ }^{[3]}$

Cerrahi teknik açısından açık ve artroskopik Latarjet karşılaştırması yapan birçok çalışma; erken dönemde artroskopik Latarjet cerrahisinin daha az ağrılı olması ve daha hızlı rehabilitasyona izin vermesi dışında, geç dönemde benzer sonuçlar verdiklerini bildirilmiştir. ${ }^{[29-31]}$

\section{Artroskopik Latarjet Cerrahi Tekniği}

Cerrahinin tekrarlanabilir ve daha kolay olmasını sağlamak için 10 basamak tanımlanmıştı. ${ }^{[7]}$ Cerrahi işlem sırasında artroskopik Latarjet seti kullanılması önerilir (DePuy Synthes Mitek, Raynham, MA, ABD).

Hastalara; ameliyat süresinin uzayabileceği ve daha konforlu cerrahi sağlayabilmek için genel anestezi yapılması önerilir. İnterskalen bölgesel blok, ameliyat sonrası analjeziye destek amacıyla eklenebilir. Pozisyonlanmada hastanın omuz rotasyonlarını serbest bırakacak şekilde olmalıdır. Cerrahi uygulanacak göğüs ön kısmının (hemitoraks) görülebilir olması ve skapula arka kısmının serbest ve görülebilir olması gerekir. Hastanın şezlong pozisyonunda hazırlanması cerrahi teknik ve cerrahi örtüm işlemini kolaylaştırmaktadır. Ameliyat esnasında cerrahi asistan ve hemşire gereksinimi bulunmaktadır. Anestezi ekibi tam bir kas gevşemesi sağlamalıdır. Ayrıca kontrollü hipotansiyon ile kanama kontrol edilerek, görüntüleme rahatlatılabilir ve artroskopi pompası kullanımını azaltılmış olur. Artroskopik pompa basıncı kontrollü olarak kullanılarak omuz bölgesinin aşırı şişmesi engellenmelidir.

Cerrahi işlem esnasında 7 portal gereksinimi bulunmaktadır. A, D, E, H, I, J, M ile portaller isimlendirilir (Şekil 7).

\section{Eklem Değerlendirmesi:}

Posterior portalin (A) ekleme tam paralel olması kontrol edilir. Glenoid ve humeral kıkırdak yüzey, rotator manşet, glenoid labrum, glenoid/humeral kemik defektleri , lezyonları [Bankart, SLAP, Hill-Sachs, ALPSA (anterior labral periosteal sleeve avulsion), HAGL (humeral avulsion of glenohumeral ligament) lezyonları] değerlendirilip kaydedilir. E-portali kullanılarak anterior yapılar daha iyi değerlendirilir. Eğer daha önce yapılmış Bankart cerrahisi varsa; greft yerleştirilme aşamasına geçilmeden çıkartılmalıdır. 
Tablo 1. Artroskopik Latarjet prosedüründe kullanılan portaller

\begin{tabular}{ll}
\hline A portalı & Posterior yumuşak doku portalidır ve ilk girişte görüntüleme için kullanılır. \\
D portalı & Akromionun hemen lateralinde yer alan anterolateral portal. \\
E portalı & Bankart tamiri sırasında kullanılan klasik anteroinferior portaldir. Rotator intervalı geçerek eklem içinde kullanılır. \\
H portalı & Korakoidin direkt üstünde yer alır. Korakoid hazırlığı ve osteotomi için kullanılır. \\
ı portalı & Korakoid doğrultusundaki aksiller portaldir. Korakoid hazırlığı sırasında görüntüleme için kullanılır. \\
J portalı & D ve ı portaller arasındaki yay boyunca uzanır. Çeşitli aşamalarda alet kullanımı ve subskapularis split sırasında kullanılır. \\
M portalı & $\begin{array}{l}\text { Medial yerleşiminden dolayı en alışılmadık portaldir. Korakoid medial kısım hazırlığı, subskapularis ayrıştırma ve greft yerleş- } \\
\text { tirme için kullanılabilir. Pektoralis minör önünde kalındığı sürece güvenlidir. Brakiyal pleksus için risk oluşturabilir. }\end{array}$
\end{tabular}

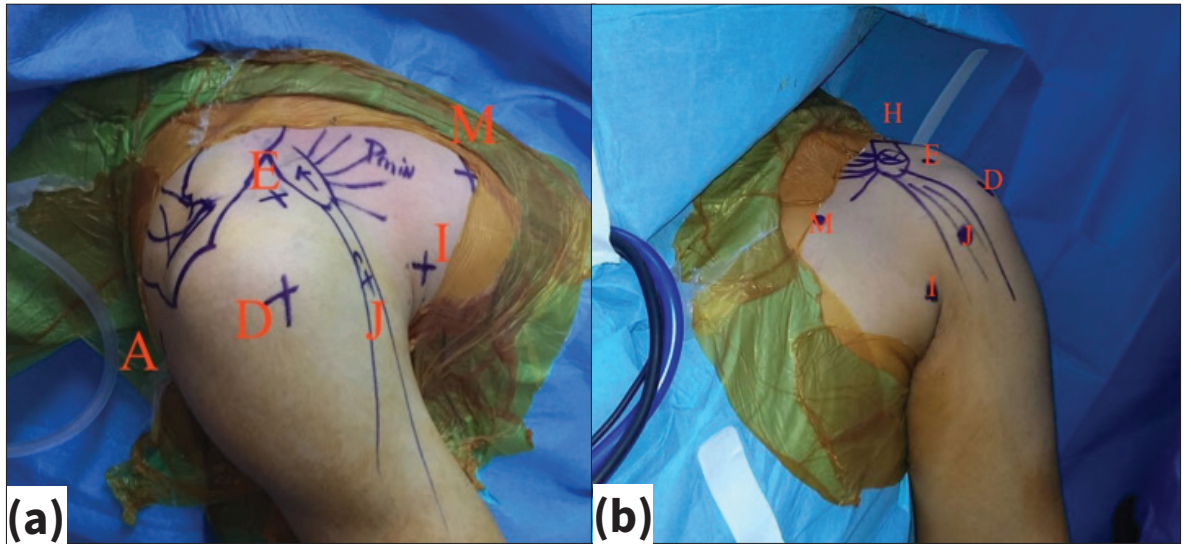

Şekil 7.a,b. Anatomik noktalar ve portallerin çizimi.

\section{Eklem içi Hazırlık:}

E portalden girilerek radyo frekans (RF) ablasyon kullanılarak glenoidin saat 2-5 arası anterior kapsül, labrum, MGHL (middle glenohumeral ligament.) ve IGHL (inferior glenohumeral ligament)'nin ön bandı rezeke edilir. Rotator interval gevşetilir ve bir iğne yardımı ile subskapularis üst kenarı belirlenerek $\mathrm{D}$ portali açılır.

\section{Korakoid Hazırlığı:}

D portali kullanılarak korakoakromial ligament korakoid den ayrilır. Konjuan tendonun laterali deltopektoral fasyadan ayrılır. Ardından artroskop D portaline taşınır ve spinal iğne yardımı ile I, J ve M portalleri açılır. M portal dikkatli açılmalıdır. Artroskop I portaldeyken M portal kullanılarak korakoid tipi ve medial duvara ulașılır. Radyo frekans kullanılarak pektoralis minör tendonu ayrılır. Brakial pleksus hasarlanmaması için RF, her zaman kemiğe yönlendirilmelidir, medial yapılar itme ve künt diseksiyon ayrıştırılabilir. D portalinden bir geçiş çubuğu (switching stick) yerleștirilerek deltoid anterior lifleri ekarte edilir ve görme alanı genişletilir. Ardından korakoid üzerindeki ve altındaki yumuşak dokular uzaklaştırılır. Bu esnada iyi koagülasyon sağlanmalıdır.

\section{Korakoid Osteotomisi:}

Artroskop I portaldeyken iğne ile $\mathrm{H}$ portal belirlenir. Ardından bu portalden çift $\mathrm{K}$ teli kılavuzu yerleştirilir. $\mathrm{K}$ teli kullanılarak korakoid tipi belirlenir ardından distaldeki tel tipten $5 \mathrm{~mm}$ uzakta olacak şekilde iki adet 1,5 mm'lik K teli gönderilir (Şekil 8). Mediolateral planda teller 2/3 lateral de olmalıdır. Korakoid, kanüllü diriller ile hazırlanır ve top hat vidaları yerleştirilir. Osteotomi hattında burr ile dekortikasyon yapılır. Eğri osteotom ile osteotomi yapılıp greft serbestleştirilir.

\section{Anterior Subskapularisi Hazırlama ve Bölme:}

Subskapularis anterior bursası uzaklaştırılarak görünür hale getirilir. Subskapularisin alt sınırını anterior humeral sirkumfleks arter ve iki ven (three sisters) belirler. Medial sınır aksiler sinir ile belirlenir. J portali görüntülemede kullanılırken $\mathrm{M}$ portalden RF ile tendonun alt $1 / 3$ ve üst $2 / 3$ birleşme yerinden başlanarak bölünür. İç 


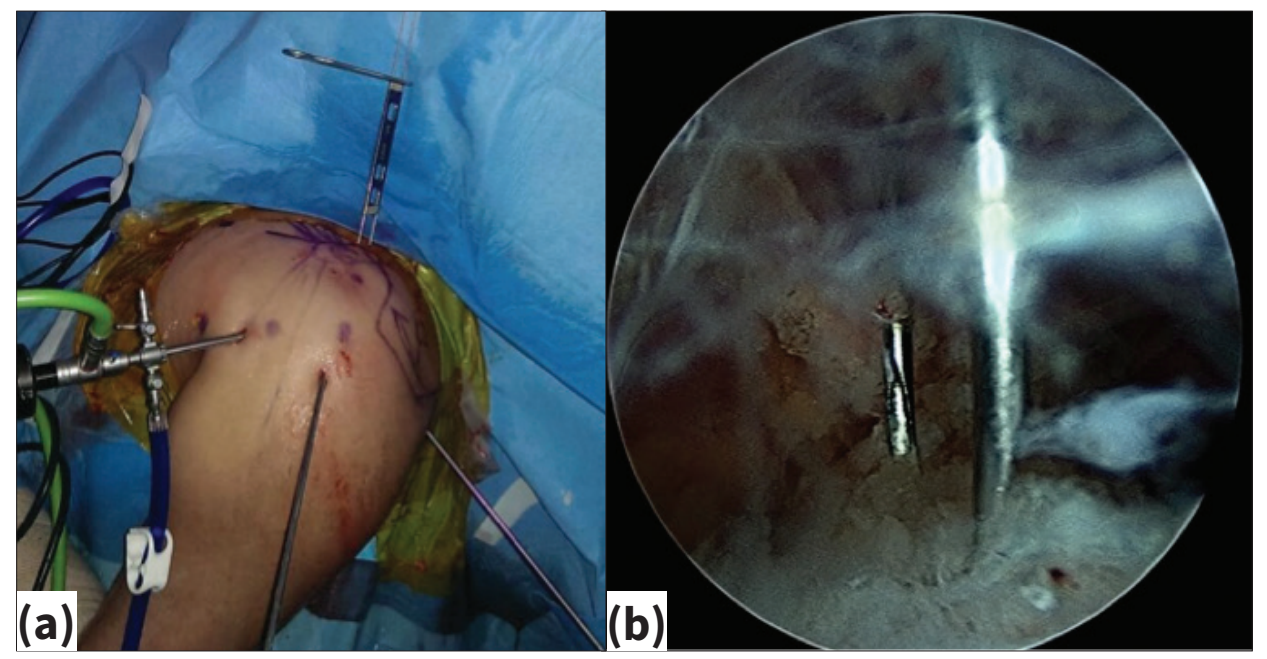

Şekil 8.a,b. Korakoide kılavuz tellerin gönderilmesi; dış görüntü (a), artroskopik görüntü (b).

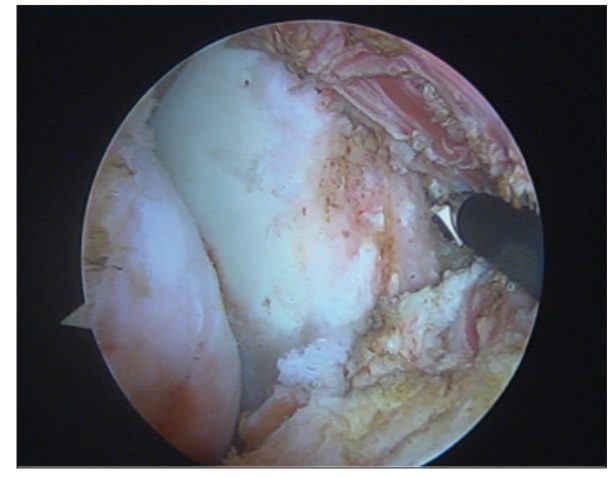

Şekil 9. Subskapularis kası split ayırma ve glenoid hazırlama.

ve dış rotasyonlar ile tüberküle kadar transvers olarak ayrıştırılır. Posterior A portalden geçiş çubuğu geçirilip ve ayrıştırmaya yardımcı olunur, brakial pleksus traksiyonu engellenir. Bu basamakta aksiller sinir potansiyel risk altında olduğundan dikkatli olunmalıdır (Şekil 9).

\section{Glenoid Hazırlığı:}

Artroskop I portalde, alet E portalden girilerek glenoid anterioru hazırlanır, dekortikasyon yapılır ve kılcal kanama görülene kadar traşlanır.

\section{Korakoidin Kılavuza Alınması:}

Plastik çift kanüllü trokar M portalden yerleştirilir ve korakoid greft tutulur. Daha önceden greftte hazırlanmış 3,5 mm kanüllü vida delikleri ve vidaların yerleştirileceği başlıklar trokar ile tam oturtulup kitlenir. Kalan yumuşak doku temizlenir ve burr ile dekortike edilir.

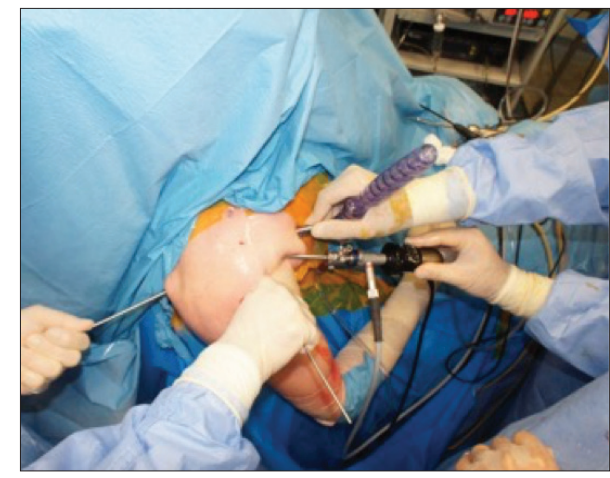

Şekil 10. Korakoid kemik blok yerleştirme (dış görüntü).

\section{Korakoidin Yerleştirilmesi:}

Greft, glenoid anterioruna yerleştirlip A portalden geçirilen geçiş çubuğu ile hizalama yapılabilir. Greft yerleşimi eklem hattının lateralinde olmamalıdır. Tutucu trokar üzerinden iki adet $1,5 \mathrm{~mm} \mathrm{~K}$ teli ile greft glenoide tutturulur ve skapula posteriorundan geçilip ciltten çıkartılır. $\mathrm{K}$ telleri ile posteriordan gelen geçiş çubuğu arasında yaklaşık $10^{\circ}$ açı bulunması önerilir (Şekil 10).

\section{Korakoid Fiksasyonu:}

Illk alttaki alfa tutma vidası çıkartılıp ve 3,2 mm'lik kanüle dril ile delinir. Posterior korteks geçilerek vida boyu (genelde $26-32 \mathrm{~mm}$ ) belirlenir ve vida ile tespit sağlanır. Aynı işlem üst vida içinde tekrarlanır. Tam kompresyon için vidalar değişmeli olarak sıkılır. Çok sıkılması grefti kırabilir veya medialize edebilir. Aşırı uzun vida kullanımından sakınılmalıdır. 


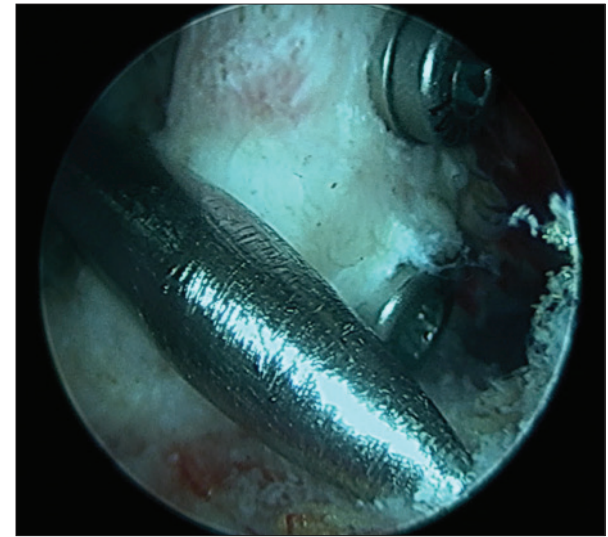

Şekil 11. Korakoid fiksasyon sonrası eklem içi artroskopik değerlendirme.

\section{Nihai Dinamik Eklem Değerlendirmesi:}

Greft pozisyonu I ve J portallerinden değerlendirilir. ideal pozisyon saat 2-5 hizasında olmalıdır. Daha sonra $\mathrm{K}$ telleri posteriordan çıkartılır. Greftin çıkıntılı olması durumunda hafifçe burr ile tıraşlanabilir. Vida başının humerus başına temas etmediği kontrol edilmelidir. Sling efekti adduksiyon ve dış rotasyonda görülebilir (Şekil 11).

Artroskopik Latarjet prosedürü, deneyimli ve yetenekli artroskopik cerrahların elinde güvenli ve tekrarlanabilir bir prosedürdür. Latarjet ameliyatındaki her aşamaya, açık cerrahide tam anlamıla hakim olduktan sonra, artroskopik yaklaşıma başlamak, en sağlıklısı olacaktır. Yukarıdaki aşamaların herhangi birinde problem yaşanması halinde açık tekniğe dönüş her zaman mümkün olacaktır.

\section{B. ALLOGREFT SEÇENEKLERi}

Bir glenoid defekt rekonstrüksiyonuna yardımcı olmak için kullanılan allogreftler ile donör saha morbiditesinden kaçınılırken büyük miktarda hazır kemik stoğu temin etmek en büyük avantajlarıdır. Allogreftler ek maliyet oluşturmaktadır. Literatürde tanımlanmış olan glenoid kemik kaybı tedavisi için allogreft seçenekleri arasında iliak krest, femur başı, humerus başı, glenoid, distal tibial, demineralize süngerimsi kemik matrisi ve ksenogreft bulunur. Allogreftin hazırlanması zor olabilir. Bir çalışma tezgahının kullanılması greft hazırlığını iyileştirebilir, hastanın ve cerrahın zarar görmesini önleyebilir. ${ }^{[25]}$

\section{Distal Tibia Allogreft Transferi}

Taze bir osteokondral distal tibia allogreftinin (DTA) kullanımı, anterior glenoid kemik kaybının rekonstrüksiyonu için nispeten yeni bir yaklaşımdır. Provencher ve ark. orijinal tekniği; \%30'dan fazla glenoid kemik kaybı olan hastalarda glenoidi yeniden yapılandırmak için distal tibianın lateral yönünün kullanıldığı küçük bir vaka serisinde tanımlamışlardır. ${ }^{[32]}$

Distal tibianın lateral yönü kullanılır, çünkü eğriliği doğal glenoidin eğriliğine benzer ve böylece daha anatomik bir rekonstrüksiyon sağlanır. Ayrıca DTA glenoid kemik kaybı alanıyla oldukça uyumlu olan bir eğrilik yarıçapına sahip kıkırdaklı bir seçenektir. Distal tibia allogrefti, Latarjet tekniği kullanılarak yeniden yapılandırılamayan büyük glenoid kusurları için iyi bir alternatif olabilir. Erken veriler umut verici olsa da daha fazla çalışmaya ve uzun vadeli verilere ihtiyaç vardır. ${ }^{[25]}$

Tekrarlayan instabilite riskini greft osteolizisi ile dengelemek önemli olduğundan, subkritik kemik kaybı (\%13,5 veya daha fazla) için optimal tedavinin belirlenmesi hala cevaplanmamış bir sorudur. Birden fazla vida tipi ve materyali mevcut olduğundan, greft fiksasyonu için en uygun tekniği belirlemek için ek araştırmalar gereklidir. Osteolizisin greft sabitleme gücü ile ilişkili olup olmadığı hâlâ bilinmemektedir.

Glenoid kemik kaybının yönetiminde artan ilgi ve araştırmalar, yeni cerrahi tekniklerin ve greft seçeneklerinin geliştirilmesine yol açmıştır. Gelişmiş görüntüleme teknolojisi, cerrahi planlama için glenoid kemik kaybını teşhis etmek ve doğru bir şekilde ölçmek için yeni seçenekler sunmaktadır. Cerrahi tedavi de, tarihi Latarjet prosedüründen doğal glenoid ile anatomik olarak daha iyi uyum sağlayabilecek, tekrarlayan instabilite ve erken glenohumeral artrit riskini azaltabilecek yeni teknikler ve greft seçeneklerine doğru evrilmiştir. Latarjet prosedürü altın standart olarak kalırken, büyüyen bir literatür, yeni tekniklerin kullanımı için iyi kanıtlar sunmaktadır. Başarısız Latarjet veya büyük miktarda kemik kaybı olan hasta alt grubunda, rekonstrüksiyon seçenekleri olarak klasik iliak krest kemik grefti veya distal tibia allogrefti kullanılabilmektedir.

Glenoid anterior kenar rekonstrüksiyonlarında kemik blok işlemleri deneyimli ve yetenekli cerrahların elinde güvenli ve tekrarlanabilir bir prosedürdür. Bu teknik, basamaklarında ince ayar yaparak hataların önlenmesinde mantıksal bir sıralama sağlayan modern araçlarla sürekli geliştirilmektedir. Kemik blok ameliyatındaki her aşamaya, açık cerrahide tam anlamıyla hakim olduktan sonra, artroskopik yaklaşıma başlamak, en sağlıklısı olacaktır. Son senelerde gelişen ve popülaritesi artan artroskopik girişimler içerisinde öğrenme eğrisi uzun ve zor olan bu cerrahinin, tecrübelerle daha tekrarlanabilir ve basitleştirilmesi en önemli beklentilerden biri olarak düşünülmektedir. 


\section{KAYNAKLAR}

1. Dodson CC, Cordasco FA. Anterior glenohumeral joint dislocations. Orthop Clin North Am 2008;39(4):507-18. Crossref

2. Burkhart SS, De Beer JF. Traumatic glenohumeral bone defects and their relationship to failure of arthroscopic Bankart repairs: significance of the inverted-pear glenoid and the humeral engaging Hill-Sachs lesion. Arthroscopy 2000;16(7):677-94. Crossref

3. Joshi MA, Young AA, Balestro JC, Walch G. Latarjet-Patte procedure for recurrent anterior shoulder instability in contact athletes. Orthop Clin North Am 2015;46(1):105-11. Crossref

4. Anakwenze OA, Hsu JE, Abboud JA, Levine WN, Huffman GR. Anterior shoulder instability associated with bony defects. Orthopedics 2011;34(7):538-44; quiz 545-6. Crossref

5. Provencher MT, Ghodadra N, LeClere L, Solomon DJ, Romeo AA. Anatomic osteochondral glenoid reconstruction for recurrent glenohumeral instability with glenoid deficiency using a distal tibia allograft. Arthroscopy 2009;25(4):446-52 Crossref

6. Schmid SL, Farshad M, Catanzaro S, Gerber C. The Latarjet procedure for treatment of recurrence of anterior instability of the shoulder after operative repair: a retrospective case series of forty-nine consecutive patients. J Bone Joint Surg Am 2012 6;94(11):e75. Crossref

7. Jouve F, Graveleau N, Nové Josserand L, Walch G. Recurrent anterior instability of the shoulder associated with full thickness rotator cuff tear: results of surgical treatment. Rev Chir Orthop Reparatrice Appar Mot 2008;94(7):659-69. Crossref

8. Nourissat G, Delaroche C, Bouillet B, Doursounian L, Aim F. Optimization of bone-block positioting in the Bristow-Latarjet procedure: a biomechanical study. Orthop Traumatol Surg Res 2014;100(5):509-13. Crossref

9. Gupta A, Delaney R, Petkin K, Lafosse L. Complication of the Latarjet procedure. Curr Rev Musculoskelet Med 2015;8(1):5966. Crossref

10. Rosso C, Bongiorno V, Samitier G, Dumont GD, Szöllösy G, Lafosse L. Technical guide and tips on the all-arthroscopic Latarjet procedure. Knee Surg Sports Traumatol Arthrosc 2016;24(2):564-72. Crossref

11. Jankauskas L, Ru " diger HA, Pfirrmann CWA, Jost B, Gerber C. Loss of the sclerotic line of the glenoid on anteroposterior radiographs of the shoulder: a diagnostic sign for an osseous defect of the anterior glenoid rim. J Shoulder Elbow Surg 2010;19(1):151-6. Crossref

12. Edwards TB, Boulahia A, Walch G. Radiographic analysis of bone defects in chronic anterior shoulder instability. Arthroscopy 2003;19(7):732-9. Crossref

13. Stevens KJ, Preston BJ, Wallace WA, Kerslake RW.CT imaging and three- dimensional reconstructions of shoulders with anterior glenohumeral instability. Clin Anat 1999;12(5):326-36. Crossref

14. Griffith JF, Antonio GE, Tong CW, Ming CK. Anterior shoulder dislocation: quantification of glenoid bone loss with CT. AJR Am J Roentgenol 2003;180(5):1423-30. Crossref
15. Baudi P, Righi P, Bolognesi D, Rivetta S, Rossi Urtoler E, Guicciardi N, Carrara M. How to identify and calculate glenoid bone deficit. Chir Organi Mov 2005;90(2):145-52.

16. Vopat BG, Cai W, Torriani M, Vopat ML, Hemma M, Harris GJ, Schantz K, Provencher MT. Measurement of glenoid bone loss with 3- dimensional magnetic resonance imaging: a matched computed tomography analysis. Arthroscopy 2018;34(12):3141-7. Crossref

17. Yamamoto N, Itoi E, Abe H, Kikuchi K, Seki N, Minagawa H, et al.Effect of an anterior glenoid defect on anterior shoulder stability: a cadaveric study. Am J Sports Med 2009; 37(5):94954. Crossref

18. Yamamoto A, Massimini DF, DiStefano J, Higgins LD. Glenohumeral contact pressure with simulated anterior labral and osseous defects in cadaveric shoulders before and after soft tissue repair. Am J Sports Med 2014;42(8):1947-54. crossref

19. Shin SJ, Kim RG, Jeon YS, Kwon TH. Critical value of anterior glenoid bone loss that leads to recurrent glenohumeral instability after arthroscopic Bankart repair. Am J Sports Med 2017;45(9):1975-81 Crossref

20. Dickens JF, Owens BD, Cameron KL, DeBerardino TM, Masini $\mathrm{BD}$, Peck KY, et al. The effect of subcritical bone loss and exposure on recurrent instability after arthroscopic Bankart repair in intercollegiate American football. Am J Sports Med 2017; 45(8):1769-75. Crossref

21. Purchase RJ, Wolf EM, Hobgood ER, Pollock ME, Smalley CC. Hill-Sachs "remplissage": an arthroscopic solution for the engaging Hill-Sachs lesion. Arthroscopy 2008 ;24(6):723-6. Crossref

22. Yamamoto N, Itoi E, Abe H, Minagawa H, Seki N, Shimada Y, et al. Contact between the glenoid and the humeral head in abduction, external rotation, and horizontal extension: a new concept of glenoid track. J Shoulder Elb Surg 2007;16(5):64956. Crossref

23. Ranalletta M, Tanoira I, Bertona A, Maignon G, Bongiovanni S, Rossi LA. Autologous tricortical iliac bone graft for failed Latarjet procedures. Arthrosc Tech 2019;8(3):e283-9 Crossref

24. Villatte G, Spurr S, Broden C, Martins A, Emery R, Reilly P. The Eden- Hybbinette procedure is one hundred years old! A historical view of the concept and its evolutions. Int Orthop 2018;42(10):2491-5. Crossref

25. Cardenas G, Ricks M, Woodmass J, Chelli M, Boileau P. Arthroscopic management of anterior glenoid bone loss. J Bone Joint Surg Am Rvw 2020;8(2):e0049. Crossref

26. Auffarth A, Schauer J, Matis N, Kofler B, Hitzl W, Resch H. The J-bone graft for anatomical glenoid reconstruction in recurrent posttraumatic anterior shoulder dislocation. Am J Sports Med 2008;36(4):638-47. Crossref

27. Kraus N, Amphansap T, Gerhardt C, Scheibel M. Arthroscopic anatomic glenoid reconstruction using an autologous iliac crest bone grafting technique. J Shoulder Elb Surg 2014;23(11):1700-8. Crossref 
28. Tokish JM, Fitzpatrick K, Cook JB, Mallon WJ. Arthroscopic distal clavicular autograft for treating shoulder instability with glenoid bone loss. Arthrosc Tech 2014;3(4):e475-81. Crossref

29. Marion B, Klouche S, Deranlot J, Bauer T, Nourissat G, Hardy P. A prospective comparative study of arthroscopic versus MiniOpen Latarjet procedure with a minimum 2-year follow-up. Arthroscopy 2017;33(2):269-77. Crossref

30. Nourissat G, Neyton L, Metais P, Clavert P, Villain B, Haeni D, et al; French Arthroscopic Society. Functional outcomes after open versusu arthroscopic Latarjet procedure: A prospective comparative study. Orthop Traumatol Surg Res 2016;102(8S):S277-S9. Crossref
31. Ali J, Altintas B, Pulatkan A, Boykin RE, Aksoy DO, Bilsel K. Open versus arthroscopic Latarjet procedure for the treatment of chronic anterior glenohumeral instability with glenoid bone loss. Arthroscopy 2020;36(4):940-9. Crossref

32. Provencher MT, Ghodadra N, LeClere L, Solomon DJ, Romeo AA. Anatomic osteochondral glenoid reconstruction for recurrent glenohumeral instability with glenoid deficiency using a distal tibia allograft. Arthroscopy 2009;25(4):446-52. Crossref 